\title{
Growth and Activity of Juvenile Mosquitofish: Temperature and Ration Effects
}

\author{
Wayne A. Wurtsbaugh ${ }^{1}$ and Joseph J. Cech, Jr. \\ Wildlife and Fisheries Biology, University of California, Davis \\ Davis, California 95616
}

\begin{abstract}
The effects of constant temperatures $(10,15,20,25,30$, and $35 \mathrm{C})$ and ration size on the growth rates and activity of juvenile mosquitofish Gambusia affinis (mean wet weight, about 20 mg) were measured in laboratory experiments. On ad libitum rations of Tubifex spp. worms, food-consumption rates of mosquitofish were very high, ranging from $7 \%$ dry body weight/day at $10 \mathrm{C}$ to $83 \%$ /day at $35 \mathrm{C}$. Growth increased from $0 \%$ dry body weight/day at $10 \mathrm{C}$ to $21 \%$ / day at $30 \mathrm{C}$ and declined slightly at $35 \mathrm{C}$. Gross efficiencies (100 growth/food consumption) increased from 0 at $10 \mathrm{C}$ to a peak of $28 \%$ at $30 \mathrm{C}$ and declined slightly at $35 \mathrm{C}$. On reduced rations ( $20 \%$ of dry body weight/day) maximum growth rates occurred at $25 \mathrm{C}$. Weight loss of starved fish varied from $1.5 \% /$ day at $10 \mathrm{C}$ to approximately $13 \% /$ day at $35 \mathrm{C}$. Fish activity increased significantly with temperature and was generally highest at intermediate feeding levels.

Received August 30, 1982

Accepted June 7, 1983
\end{abstract}

Since the pioneering work of Gerking (1962), Warren and Davis (1967), and Brett et al. (1969), the relationships among temperature, food consumption, and growth rates of fish have received much attention (for review, see Brett 1979). Because of experimental difficulties, few people have investigated the interaction of temperature and food-consumption rate on the growth of fish during their early weeks of feeding. However, this period is important if production processes in aquaculture and in field environments are to be understood, because mortality is often very high at this time. This period is also interesting because growth rates of fish larvae and small juveniles feeding ad libitum are much higher than those of larger juveniles (see Strawn 1961; Hokanson et al. 1973; McCormick et al. 1977; Brett 1979).

Ration levels and temperature also affect fish activity. Activity typically increases with increasing temperature (Brown 1957). However, effects of ration level on activity are poorly understood. The theoretical relationship between food supply and the energy costs of activity (see review by Webb 1978) indicates reduced rations should limit activity. Ecologically, 'Present address: Department of Fisheries and
Wildlife, UMC 52, Utah State University, Logan, Utah
84322 . limitations on activity might have significant effects on a species' predator-prey interactions.

Here we report results of laboratory experiments on how temperature and ration level interact to affect the growth and activity of 10day-old mosquitofish Gambusia affinis weighing approximately $20 \mathrm{mg}$. Using regression techniques, we constructed an empirical model relating growth rates to food consumption and temperature. This model can be used to predict food consumption rates of wild mosquitofish if their growth rates and habitat temperatures are known (Davis and Warren 1968).

\section{Methods}

\section{Experimental Apparatus and Design}

Experiments followed a factorial design of six temperatures and four ration levels. A water bath $(1.1 \times 0.6 \times 0.4 \mathrm{~m})$ housed four 32 -liter glass aquaria for each temperature treatment; each aquarium was fitted with a translucent lid and assigned a ration treatment. All water baths were in a cold room held within $0.5 \mathrm{C}$ of $10 \mathrm{C}$. Water temperatures higher than $10 \mathrm{C}$ were maintained within $0.5 \mathrm{C}$ of target with immersion heaters controlled by thermoregulator and relay systems. Lighting of the experimental apparatus came from two 75-watt incandescent bulbs. Irradiance measured at the $600 \mathrm{~nm}$ wavelength at the tank surface was $2 \times 10^{11}$ photons . $\mathrm{cm}^{-2} \cdot \mathrm{nm}^{-1} \cdot$ second $^{-1}$ (about $50 \mathrm{lux}$ ). 
Water circulation, aeration, and filtration were accomplished with airlift pumps. Water was pumped out of each aquarium at a mean flow of 1.3 liters/minute to a gravel filter; it flowed by gravity back through the water bath, and entered the aquaria through standpipes covered with $150-\mu \mathrm{m}$ screen. In addition, $75 \%$ of the water in each water bath was replaced at 2-day intervals with unchlorinated well water. Periodic measurements in the aquaria showed the following characteristics: dissolved oxygen, 96-100\% of saturation; $\mathrm{pH}, 8.5-8.7$; hardness, $255 \mathrm{mg} /$ liter as $\mathrm{CaCO}_{3}$; total alkalinity $320 \mathrm{mg}$ / liter as $\mathrm{CaCO}_{3}$.

The experimental apparatus allowed the concurrent operation of four temperature treatments. The first series of experiments (A) were conducted at 10,15, 25, and $35 \mathrm{C}$. Series-B experiments were at 20 and $30 \mathrm{C}$. Because growth rates were expected to differ greatly with temperature, the experimental periods were adjusted to minimize the confounding effects of fish size (Wurtsbaugh and Davis 1977; Brett 1979). Treatments were terminated at approximately 175 degree-days (for example, 10 $\mathrm{C}$ experiments lasted 18 days and $35 \mathrm{C}$ experiments lasted 5 days).

\section{Experimental Fish}

Large numbers of mosquitofish larvae were simultaneously produced for experiments. Pregnant females were collected from stock at Wheatland, California, and held in the laboratory in groups under constant illumination to inhibit parturition. Up to 115 females then were placed in individual breeding chambers with screen-mesh bottoms in a large tank and held in darkness overnight at $20 \mathrm{C}$. The juveniles produced were held 3 days at $20 \mathrm{C}$ and fed ad libitum on Artemia salina nauplii and tubificid worms. From birth until the end of the experiment the juvenile mosquitofish were held in the laboratory under a photoperiod of 16 hours light, 8 hours darkness. The experiments were conducted from August 18 to September 10, 1979 .

Two hundred fish per temperature treatment were moved to aquaria in the appropriate water bath and acclimated 7 days. Temperature was changed $2 \mathrm{C} /$ day until the experimental temperature was reached. During the acclimation period fish were fed maintenance rations plus $30 \%$ of body weight/day to minimize differ- ences in growth among temperature treatments. Maintenance rations were predicted from respiration-rate measurements of juvenile mosquitofish at different temperatures (Winberg 1956). Despite these attempts to start experiments with similar-sized fish, fish did grow somewhat differently during acclimation. Thus, mean wet weights at the start of the experiment varied from 12.1 to $16.8 \mathrm{mg}$ among temperature treatments (Table 1).

\section{Weighing}

Of the 200 acclimated fish in each treatment group, 150 intermediate-sized individuals were randomly divided into five lots. Four lots were randomly assigned to a feeding treatment. Fish in the fifth lot were sacrificed in $200 \mathrm{mg}$ /liter tricaine methanesulfonate and immediately weighed and measured to estimate the initial size and moisture content of the test fish. Fish were starved 20 hours before initial and final weighings. Individual fish were dipped in acetone for 15 seconds, blotted on a paper towel for 30 seconds, air-dried for 60 seconds, and weighed to the nearest $0.1 \mathrm{mg}$. Coefficient of variation $(\mathrm{SD} /$ mean) for initial wet weights within a feeding treatment was $16 \%$. Standard lengths were measured to the nearest $0.1 \mathrm{~mm}$. Fish then were dried to constant weight at 60 C (24 hours).

\section{Feeding}

Fish were fed on a diet of Tubifex spp. worms, which were purchased commercially and maintained in a mud and manure mixture. Tubificid worms were used because they are readily accepted by juvenile mosquitofish and uneaten portions could be quantified. The worms were held in clean water for 24 hours before they were used. A bolus of worms for each aquarium was cut into eight parts to facilitate feeding by the small fish. A subsample of worms was taken daily and dried $(24$ hours at $60 \mathrm{C})$ to estimate dry weights of food fed. Mean dry-matter content of worms was $21.0 \pm 1.0 \%$ (SD) in series-A experiments and $21.3 \pm 1.0 \%$ in seriesB tests. The four ration levels were: (a) $10-20 \%$ excess (for ad libitum feeding); (b) approximately one-half of the ad libitum ration; (c) quantities estimated to support body maintenance; (d) no food. Just prior to feedings, tanks were siphoned clean, and any uneaten food was dried and weighed. 
It was expected that the worm fragments would lose weight in the tanks because of leaching and residual metabolism. Two 24-hour trials to estimate these losses showed $0 \%$ loss at 10 $20 \mathrm{C}$ to $18 \%$ weight loss at 30 and $35 \mathrm{C}$. No corrections for these losses were made because most or all of the worms were eaten by the fish within a few hours, but consumption rates at high temperatures could have been overestimated by a few percent as a result.

During preliminary experiments, starved fish were seen feeding at the surface of the tanks and ciliated protozoans $(60 \mu \mathrm{m} \times 30 \mu \mathrm{m})$ were found in their gastrointestinal tract. Digestion of protozoans seemed minimal as they appeared intact throughout the tracts. Throughout subsequent experiments, water was changed more frequently and this feeding behavior was not observed. However, guts of fish dissected at the conclusion of experiment A were filled to 5$10 \%$ of capacity with unidentifiable "detrital" material, indicating fish may have been getting some additional nutrition (unauthorized feeding) other than that from rations offered. To test this, during experiment series B, groups of 10 juveniles were placed in 1-liter bottles with aeration at 20, 25, and $30 \mathrm{C}$ to compare starvation weight loss rates with those in the main growth study. Approximately $90 \%$ of the water was changed daily to reduce microbial growth in the bottles and no air was allowed at the top for development of neuston. Weight loss was measured in the same manner as in the growth experiments.

In one further experiment, we investigated effects of dietary variety on growth. Artemia salina nauplii or tubificid worms were offered to 30 newborn mosquitofish in each of two aerated aquaria maintained at $20 \pm 1 \mathrm{C}$. Fish were fed once daily in the morning and water was changed at 4-5-day intervals. Excess food was always present but Artemia nauplii were always dead the following morning. Ten fish were removed from each aquarium at 5-10-day intervals for measurements of individual wet weights and pooled dry weights.

\section{Activity}

Fish activity levels were measured five times during the experiments. Only two measurements were taken of the $35 \mathrm{C}$ treatment groups: these were highly variable and were not included in the analyses. Activity was measured 2-4 hours after feeding by two methods. One involved counting the number of times in $1 \mathrm{~min}$ ute that fish crossed through the vertical projection of a $5 \mathrm{~cm} \times 5 \mathrm{~cm}$ plastic square placed on bottom-center of each aquarium. The second method consisted of visual estimates of swimming speed (body lengths/second) of individual fish for approximately 1 minute. Temperature and ration ( 0 , low, high, repletion) effects on activity were tested by a two-way analysis of variance with the five observations entered as a replication measure (Dixon 1981). Consequently, a temperature-ration interaction could not be calculated.

\section{Calculations}

Instantaneous (=specific) growth rates $(G)$ expressed as \% dry body weight/day were calculated from

$$
G=100 \frac{\log _{e} W_{2}-\log _{e} W_{1}}{t} ;
$$

$W_{1}=$ mean initial estimated dry weight;

$W_{2}=$ mean final dry weight;

$t=$ duration of experiment (days).

Instantaneous food consumption rates $(C)$, expressed as \% body weight/day, were calculated as

$$
C=100 \frac{F}{W_{1} \cdot e^{(G t / 2)}} ;
$$

$$
\begin{aligned}
F= & \text { mean dry weight of food }(\mathrm{g}) \text { consumed } / \\
& \text { fish daily. }
\end{aligned}
$$

The instantaneous food consumption rate was derived to calculate the dry weight of the fish midway through the experiment, rather than the mean weight during the experiment (average relative consumption rate). Gross conversion efficiencies $(G E)$ were calculated as

$$
G E=100 \frac{W_{2}-W_{1}}{F \cdot t}
$$

\section{Results}

The small mosquitofish juveniles showed remarkably high capacities for food consumption, growth, and weight loss (Table 1). A curvilinear relationship between instantaneous food-consumption rate and instantaneous growth was exhibited at all temperatures (Fig. 1). As a consequence, conversion efficiencies peaked at intermediate ration levels (Fig. 2). 
TABLE 1.-Mean temperatures, duration of each experiment, food-consumption rates (dry), initial and final wet weights, dry weights (as \%), and standard lengths of mosquitofish studied.

\begin{tabular}{|c|c|c|c|c|c|c|c|c|}
\hline \multirow{2}{*}{$\begin{array}{l}\text { Experi- } \\
\text { mental } \\
\text { temper- } \\
\text { ature } \\
\text { (C) }\end{array}$} & \multirow{2}{*}{$\begin{array}{c}\text { Experi- } \\
\text { ment } \\
\text { dura- } \\
\text { tion } \\
\text { (days) }\end{array}$} & \multirow{2}{*}{$\begin{array}{c}\text { Dry food } \\
\text { consump- } \\
\text { tion rate } \\
\left(\mathrm{mg} \cdot \mathrm{day}^{-1}\right. \\
\left.\cdot \text { fish }^{-1}\right)\end{array}$} & \multicolumn{3}{|c|}{ Initial fish size } & \multicolumn{3}{|c|}{ Final fish size } \\
\hline & & & $\begin{array}{c}\text { Wet } \\
\text { weight } \\
\text { (mg) }\end{array}$ & $\begin{array}{c}\text { Dry } \\
\text { weight } \\
(\%)\end{array}$ & $\begin{array}{c}\text { Standard } \\
\text { length } \\
(\mathrm{mm})\end{array}$ & $\begin{array}{c}\text { Wet } \\
\text { weight } \\
(\mathrm{mg})\end{array}$ & $\begin{array}{c}\text { Dry } \\
\text { weight } \\
(\%)\end{array}$ & $\begin{array}{c}\text { Standard } \\
\text { length } \\
(\mathrm{mm})\end{array}$ \\
\hline 10.0 & 18 & 0.00 & 12.1 & 19.8 & 8.4 & 10.5 & 19.0 & 8.4 \\
\hline 10.0 & & 0.06 & & & & 11.7 & 18.8 & 8.6 \\
\hline 10.0 & & 0.08 & & & & 12.0 & 19.2 & 8.5 \\
\hline 10.0 & & 0.16 & & & & 12.5 & 19.2 & 8.6 \\
\hline 15.0 & 12 & 0.00 & 12.4 & 21.0 & 8.8 & 11.2 & 17.0 & 8.8 \\
\hline 15.0 & & 0.16 & & & & 13.8 & 18.8 & 8.9 \\
\hline 15.0 & & 0.41 & & & & 15.3 & 20.3 & 9.1 \\
\hline 14.9 & & 0.62 & & & & 15.4 & 20.1 & 9.5 \\
\hline 20.0 & 9 & 0.00 & 14.1 & 19.1 & 9.0 & 11.4 & 18.4 & 9.2 \\
\hline 20.0 & & 0.24 & & & & 14.2 & 20.4 & 9.5 \\
\hline 20.1 & & 0.63 & & & & 19.2 & 20.8 & 10.4 \\
\hline 19.9 & & 1.32 & & & & 23.7 & 21.5 & 11.1 \\
\hline 24.7 & 7 & 0.00 & 15.6 & 21.2 & 9.8 & 14.4 & 18.8 & 9.6 \\
\hline 25.0 & & 0.48 & & & & 20.3 & 20.7 & 10.3 \\
\hline 24.9 & & 1.60 & & & & 30.0 & 22.0 & 11.9 \\
\hline 25.0 & & 3.02 & & & & 41.3 & 22.3 & 13.0 \\
\hline 30.1 & 6 & 0.00 & 15.0 & 19.3 & 9.2 & 9.6 & 16.7 & 8.5 \\
\hline 29.9 & & 0.54 & & & & 17.4 & 20.1 & 9.6 \\
\hline 29.9 & & 2.09 & & & & 28.9 & 21.5 & 11.5 \\
\hline 30.0 & & 4.26 & & & & 46.0 & 22.4 & 12.9 \\
\hline 35.0 & 5 & 0.00 & 16.8 & 19.6 & 9.7 & 12.1 & 17.4 & 9.0 \\
\hline 34.8 & & 0.88 & & & & 19.9 & 21.6 & 9.9 \\
\hline 35.2 & & 2.46 & & & & 29.5 & 22.7 & 11.7 \\
\hline 35.0 & & 4.54 & & & & 38.2 & 24.1 & 12.5 \\
\hline
\end{tabular}

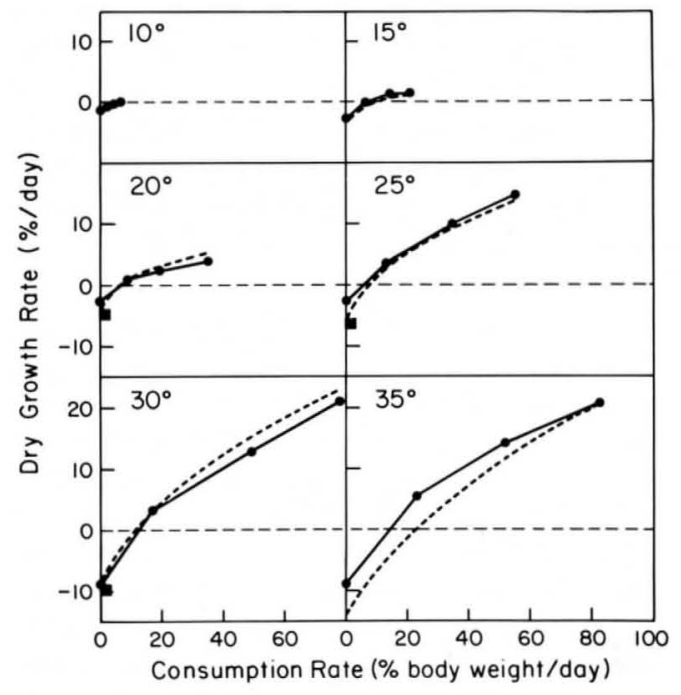

FIGURE 1.-Effects of instantaneous food-consumption rates on instantaneous growth rates of mosquitofish larvae at six temperatures. The dashed lines were calculated from a model (Equation 8) of the empirical data.
In ad libitum feeding regimes the food-consumption rates and growth of fish were strongly influenced by temperature (Fig. 2). Maximum food-consumption rates increased exponentially from $7 \%$ of body weight/day at $10 \mathrm{C}$ to $78 \%$ / day at $30 \mathrm{C}$. Further temperature increase to $35 \mathrm{C}$ resulted in only a slight increase in food consumption to $82 \%$ /day. Growth was zero at $10 \mathrm{C}$. With increases in temperature, growth rates increased exponentially to a maximum of $21 \% /$ day at $30 \mathrm{C}$, equivalent to a weight-doubling time of 3.3 days. At $35 \mathrm{C}$, growth rate decreased slightly. Consequently, the optimal temperature for growth of mosquitofish juveniles with unlimited food lies somewhere between 25 and $35 \mathrm{C}$. Gross conversion efficiency was zero at $10 \mathrm{C}$, increased rapidly to a plateau of approximately $28 \%$ between 25 and $30 \mathrm{C}$, and declined slightly to $25 \%$ at $35 \mathrm{C}$.

Under food-limited conditions, the optimal temperature for growth of mosquitofish juveniles was reduced. Estimated growth rates at the 


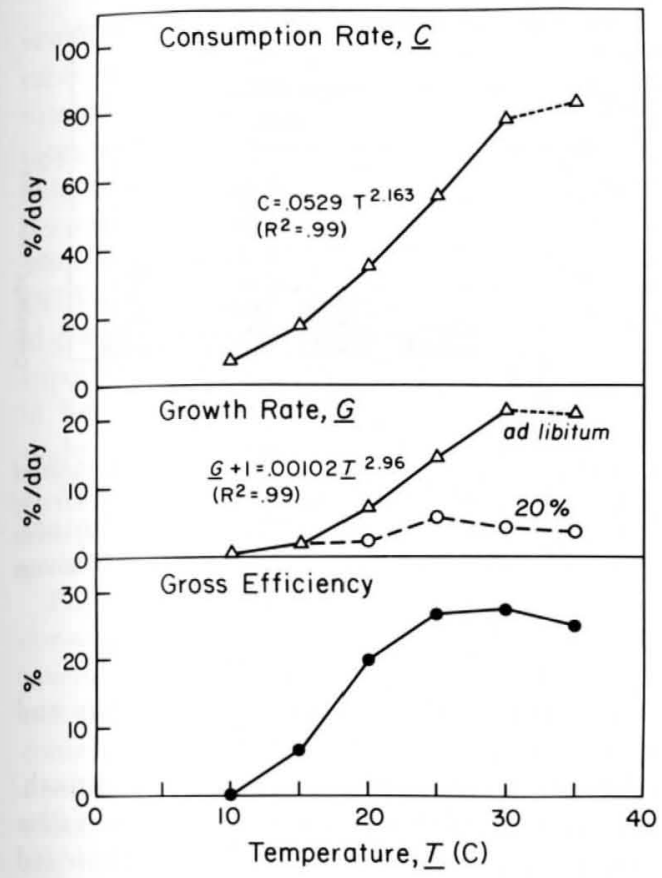

FigURE 2.-Effects of temperature on instantaneous foodconsumption rate, instantaneous growth rate, and gross efficiency, of juvenile mosquitofish fed ad libitum. Growth rates of fish fed at $20 \%$ of their body weight per day also are shown. All data are based on dry weights of fish and food. Regression lines for consumption and growth rates were fitted for temperatures from 10 to $30 \mathrm{C}$.

$20 \%$ /day ration level were calculated from Fig. 1. At this limited ration, growth rates were greatly reduced and the temperature optimum for growth shifted to $25 \mathrm{C}$ (Fig. 2). With restricted feeding, a reduction of temperature optima for growth occurs in most species (Brett 1979; Beitinger and Magnuson 1979). Dryweight percentage of the fish increased with increasing ration size, particularly at warmer temperatures (Table 1).

Weight loss of starved mosquitofish increased exponentially from $1 \% /$ day at $10 \mathrm{C}$ to approximately $13 \% /$ day at $35 \mathrm{C} \mathrm{(Fig.} \mathrm{3).} \mathrm{The} \mathrm{weight}$ loss of fish kept in bottles from which we carefully excluded protozoa and detritus was markedly higher than in aquaria in two of the three comparative treatments. This suggests that growth rates of fry reared in aquaria on low rations may have been overestimated due to unmeasured feeding.

From regression analysis, an empirical model of the data was constructed that describes growth

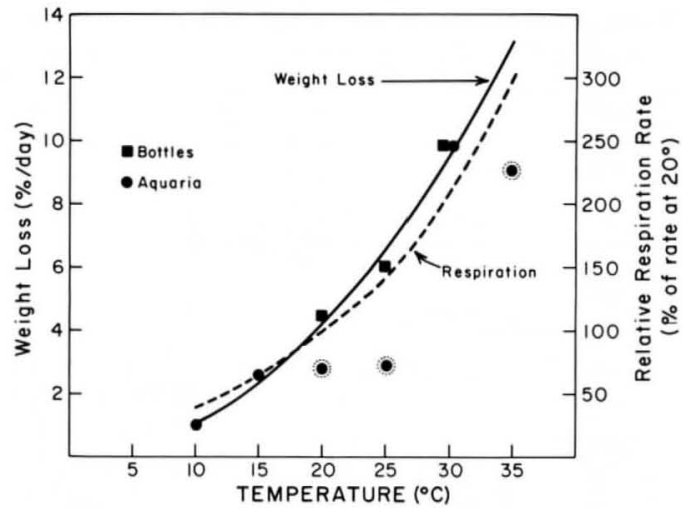

Figure 3.-The effect of temperature on weight loss of "starved" juvenile mosquitofish reared in aquaria and in bottles. Circled points, which probably were affected by feeding of fish on detritus or protozoa, were not used to fit regression. The relation between weight loss (y) and temperature $(\mathrm{x})$ was fit by $\mathrm{y}=0.0105 \mathrm{x}^{2.008} ; \mathrm{r}^{2}=0.99$.

For comparative purposes the relationship between temperature and respiration rate of 0.5-g mosquitofish larvae (derived from Cech et al. 1980) is also shown.

rate as a function of temperature and consumption rate. The relationships between consumption rates $(C)$ and growth rates $(G)$ at each temperature were adequately described by exponential equations (Table 2 ) of the type

$$
\log _{e}(G+15)=a+b \log _{e}(C+1) .
$$

The values 15 and 1 were introduced into the equations to avoid zero or negative exponents when growth rates were negative or consumption rates zero. The intercept $a$, the estimator of growth rate at zero ration, decreases as temperature increases; the slope $b$ increases with temperature (Table 2). Both parameters can be expressed as functions of temperature $(T)$ :

TABLE 2.-Equations relating instantaneous consumption rates $(\mathrm{C}, \%$ dry body weight/day) and instantaneous growth rates $(\mathbf{G}, \% d r y$ body weight/day) of juvenile mosquitofish at different temperatures (Fig. 1). To calculate the regressions, values for grow th rate at zero ration were estimated from Fig. 3.

\begin{tabular}{ccc}
\hline $\begin{array}{l}\text { Tem- } \\
\text { pera- } \\
\text { ture }\end{array}$ & Equation & \\
\hline 10 & $\log _{e}(G+15)=2.634+0.0359 \log _{e}(C+1)$ & 0.99 \\
15 & $\log _{e}(G+15)=2.534+0.0902 \log _{e}(C+1)$ & 0.99 \\
20 & $\log _{e}(G+15)=2.356+0.2012 \log _{e}(C+1)$ & 0.99 \\
25 & $\log _{e}(G+15)=2.108+0.3130 \log _{e}(C+1)$ & 1.00 \\
30 & $\log _{e}(G+15)=1.666+0.4309 \log _{e}(C+1)$ & 1.00 \\
35 & $\log _{e}(G+15)=0.645+0.6874 \log _{e}(C+1)$ & 1.00 \\
\hline
\end{tabular}




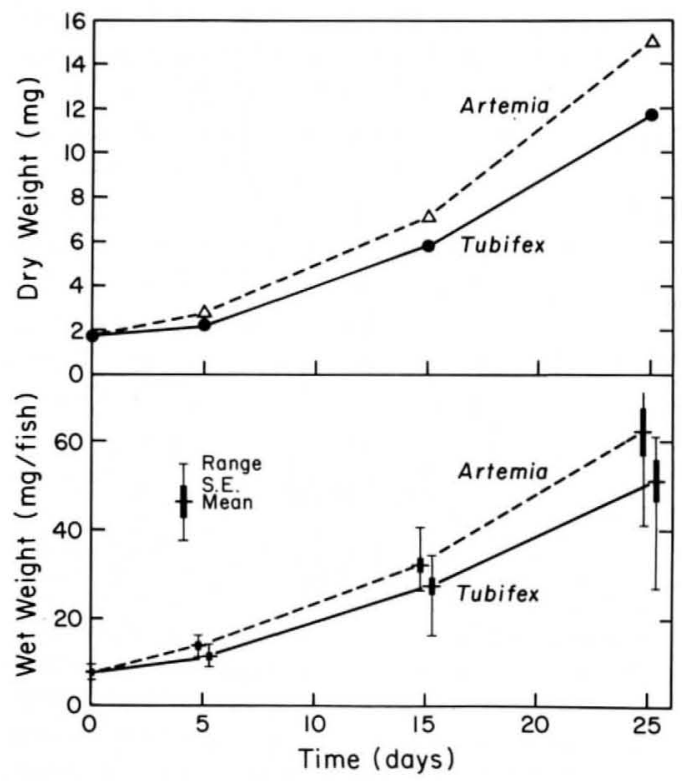

FIGURE 4.-Dry-and wet-weight growth of juvenile mosquitofish fed on diets of Artemia salina nauplii or Tubifex spp. The regression of wet weight $(\mathrm{w})$ and time $(\mathrm{t})$ for fish fed Artemia was $\mathrm{W}=7.57 \mathrm{e}^{0.0840(t+1)} ; \mathrm{R}^{2}=$ 0.99. For fish fed Tubifex the equation was $\mathrm{W}=$ $7.03 \mathrm{e}^{0.0783(\mathrm{t}+1)} ; \mathrm{R}^{2}=0.98$.

$$
\begin{array}{rlrl}
a= & 3.71-0.188 T+0.0103 T^{2} \\
& -0.00021 T^{3}, & R^{2}=0.995 ; \\
b= & 0.000170 T^{2.329}, & R^{2}=0.997 .
\end{array}
$$

Substitution of Equations (5) and (6) into Equation (4) yields

$$
\begin{aligned}
\log _{e}(G+15)= & 3.71-0.188 T \\
& +0.0103 T^{2} \\
& -0.00021 T^{3} \\
& +0.000170 T^{2.329} \\
& \cdot \log _{e}(C+1) .
\end{aligned}
$$

If the right side of Equation (7) is called $Q$

$$
G=e^{Q}-15 .
$$

The model adequately describes the empirical data except for fish fed restricted rations in the $35 \mathrm{C}$ treatment (Fig. 1). The food-consumption rates of fish in these treatments may have been considerably underestimated because of unmeasured feeding on detritus or protozoa (Fig. 2). Consequently, the model, which omitted the results at zero ration and $35 \mathrm{C}$, may give a more accurate estimate of the relation-

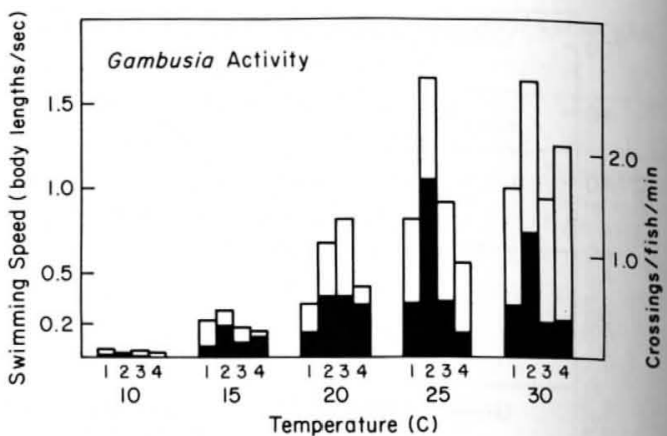

FIGURE 5.-Effect of temperature and ration on estimated swimming speeds (open bars) and activity (solid bars) of juvenile mosquitofish. Numbers $1-4$ on abscissa represent increasing ration levels from starvation (1) to ad libitum (4).

ship between actual food consumption and growth at $35 \mathrm{C}$.

Ration quality affected mosquitofish growth. Growth rates of mosquitofish fed Artemia salina nauplii were significantly higher than those fed Tubifex spp. worms $(P<0.05 ; F$-test of differences in $\log _{e}$-linear slope of growth curves). After 25 days, the mean weight of Artemia-fed fish was $22 \%$ greater than that of fish fed Tubifex spp. (Fig. 4).

Mosquitofish activity was influenced more by temperature than by feeding level (Fig. 5). As temperature changed from 10 to $30 \mathrm{C}$, mean estimated swimming speeds and movements over the plastic disk increased more than twenty-fold. Temperature effects, measured by either method, were significant at $P<0.025$. Changes in food supply generally had less than a two-fold effect on fish movements; maximum activity usually occurred at intermediate ration levels. Ration effects were significant at $P<0.06$ (crossings) or $P \leq 0.08$ (estimated swimming speed).

\section{Discussion}

Juvenile mosquitofish have a very high capacity for food consumption and growth. At 30 and $35 \mathrm{C}$, consumption rates were over $75 \%$ of body weight/day and growth rates were more than $20 \%$ day. Even these high rates are probably not maximal for very small mosquitofish, as other foods may be more readily accepted and nutritious (Fig. 4; Brett 1979). The maximum conversion efficiencies of mosquitofish $(28 \%)$ are in the range reported for larger ju- 
venile fish (Brett 1979), so the rapid growth rates are primarily a consequence of high consumption rates. Although food-consumption rates for larvae and early juvenile fish are seldom measured, growth rates over $20 \%$ /day have been reported for various species (for example, Winberg 1956; Kinne 1960; Hokanson et al. 1973; Ishibashi 1974). With adequate food, rapid growth rates of mosquitofish juveniles can be expected at temperatures between 25 and $35 \mathrm{C}$ in field and aquaculture environments. The slight decrease in growth and gross efficiencies at $35 \mathrm{C}$ suggest that as temperatures approach the incipient lethal level of 37-38 C (Otto 1973) growth may decrease considerably.

Physiologically, the high capacity for food consumption and growth of larvae and early juvenile fish follows from their high metabolic rates (Brett and Groves 1979). The ecological consequence of this high capacity is that very small fish can grow rapidly through a stage at which they are highly vulnerable to predation and starvation. Conversely, if food is not available, the high metabolic rates will cause the fish to starve to death quickly.

The effects of temperature in the present investigation contrast with the results of earlier growth studies on mosquitofish. Shakuntala and Reddy (1979) reported maximal growth in fresh water on ad libitum rations of Tubifex sp. at 25 $\mathrm{C}$, and conversion efficiencies that declined as temperature increased from 20 to $30 \mathrm{C}$. However, mortality rates in their experiment varied from 60 to $100 \%$, suggesting that their fish were suffering from an epizootic infection or some other serious stress. In another study, Shakuntala and Reddy (1977) found a maximal growth rate of only $10.5 \%$ /day at $25 \mathrm{C}$, whereas the growth rate with ad libitum feeding in our experiments was substantially higher $(14.6 \%)$ day) at this temperature. Gibson and Hirst (1955) found maximal growth at 23-25 C in another poeciliid fish, the guppy Poecilia reticulata.

Temperature and food supply both appear to influence activity of mosquitofish (Fig. 5). Maximum swimming rates at intermediate levels of food abundance may be expected on theoretical grounds (Ware 1975). When there is very little food in the environment, increases in swimming rate increase respiratory costs with little compensatory increases in food intake. Hence, weight loss can be reduced by minimal activity. At intermediate prey densities, food consump- tion can increase by increased searching activity. However, at high levels of prey abundance, food is easily found, and respiratory costs can be minimized by reducing swimming rate. Although it is difficult to extend our laboratory observations on activity to a natural environment, the responses of mosquitofish support Ware's (1975) optimal-foraging model. However, the overwhelming influence of temperature indicates that metabolic state, rather than prey availability, is more important in controlling activity of this ectothermic animal.

The food-consumption-growth-rate relationship established here (Equation 8 ) may be applicable to an understanding of growth and consumption rates of wild mosquitofish. The two diets tested, Artemia salina nauplii and tubificid worms, are representative of natural foods of mosquitofish (Hess and Tarzwell 1942), and the two foods produced only slightly different $(8 \%)$ growth rates of mosquitofish. ${ }^{2}$ Other factors such as cyclic temperatures (Hokanson et al. 1977; Medvick 1979; Cox and Coutant 1981) and swimming speed (Carline and Hall 1973; White 1978) may influence the food-consumption-growth-rate relationship, but the effects of these variables are usually small and should not seriously limit the application of laboratory data to field situations.

\section{Acknowledgments}

We are especially grateful to $\mathrm{H}$. $\mathrm{Li}$ who began the project on mosquitofish in rice fields and reviewed the manuscript. B. Vondracek provided constructive comments and reviewed the manuscript. We thank D. Raymond for typing. This study was supported by special state funds for mosquito research appropriated annually by the California Legislature and administered through the University of California.

\section{References}

Beitinger, T. L., And J. J. Magnuson. 1979. Growth rates and temperature selection of bluegill, Lepomis macrochirus. Transactions of the American Fisheries Society 108:378-382.

BRETT, J. R. 1979. Environmental factors and growth. Pages 559-675 in W. S. Hoar, D. J. Randall, and J. R. Brett, editors. Fish physiology, volume 8 . Academic Press, New York, New York, USA.

${ }^{2}$ Tubificid worms may be inadequate for long experiments as fish develop symptoms of vitamin deficiency. 
The effect of temperature on feeding rates and growth rate of grass carp and the hybrid was investigated in three aquaria maintained at 14,22 , and $30 \mathrm{C}$. These temperatures encompass the normal ranges found in midwestern lakes during spring, summer, and fall when vegetation can be a problem. Fish were brought to these temperatures at a rate of $1 \mathrm{C}$ per day. Water was recycled through a biofilter system with a 1 liter/minute flush to maintain its quality. Four hybrids and four grass carp were placed in each aquarium; the two groups were separated by a screen across the center of each tank and the drain pipe area was screened to prevent any plants from being flushed out of the system. All fish were marked by a fin clip to allow examination of individual growth rates. Najas guadalupensis, the most highly preferred macrophyte in the food-preference study, was offered ad libitum in preweighed amounts every 2 days. On every second day throughout the trial, each tank was siphoned to remove accumulated excrement, and the remaining plant material was removed and weighed. Fish were weighed at the beginning and end of each trial; each trial lasted 20 days.

In the first trial, with "small" fish, hybrids that averaged $77 \mathrm{~g}(\mathrm{SD}, 22)$ and grass carp that averaged $106 \mathrm{~g}(\mathrm{SD}, 18)$ were used in 208-liter aquaria. In the second trial, with "mediumsized" fish, hybrids averaged $273 \mathrm{~g}$ (SD, 57), grass carp averaged $230 \mathrm{~g}$ (SD, 37), and the aquarium was 1,100 liters. Both of these trials were conducted at all three temperatures. The third trial, conducted only at $30 \mathrm{C}$, involved "large" hybrids that averaged $360 \mathrm{~g}$ (SD, 36) and "large" grass carp that averaged $518 \mathrm{~g}$ (SD, 45 ) in 1,100-liter aquaria.

Water-quality variables monitored throughout the entire study included total ammonianitrogen, nitrite-nitrogen, nitrate-nitrogen, temperature, dissolved oxygen, and $\mathrm{pH}$. Water quality was acceptable during all phases of the study; total ammonia-nitrogen, nitrite-nitrogen, and nitrate-nitrogen never exceeded 0.5 , 0.05 and $1.4 \mathrm{mg} /$ liter, respectively. The lowest oxygen concentration ( $3.3 \mathrm{mg}$ /liter) occurred for 1 day in the $30 \mathrm{C}$ growth study with small fish. Temperatures in the aquaria used in the food-preference study increased gradually with each succeeding run as the ambient water supply warmed. Run 1 was conducted at $20 \mathrm{C}$, run 2 at $22 \mathrm{C}$, and run 3 at $23 \mathrm{C}$. The three exper- imental temperatures in the feeding-rate and growth study were maintained with minor fluctuations of $1 \mathrm{C}$ or less.

Isozyme analyses (Magee and Philipp 1982) were run on $50 \%$ of the experimental fish by David Philipp of the Illinois Natural History Survey. All fish were triploid.

The mean weight of both forms were statistically compared by analysis of variance and subsequent LSMEANS procedure. An alphalevel $\leq 0.05$ was used for all comparisons.

\section{Results and Discussion}

\section{Food Preferences}

Hybrids had a well-defined hierarchy of preferences among the plant foods offered: filamentous algae $>$ Najas guadalupensis $>$ Elodea nuttallii $>$ Ceratophyllum demersum (Table 1). This order occurred whether foods were offered in groups of four or two categories, though more of the less-preferred plants were eaten when alternative choices were restricted. Avault et al. (1968) reported a similar hierarchy of food preferences for grass carp $31-41 \mathrm{~cm}$, which preferred Chara sp. and N. guadalupensis over $C$. demersum. Other investigators have noted that

TABLE 1.-Consumption of filamentous algae and macrophytes by 15-20-cm hybrids of grass carp $\$ \times$ bighead carp $\delta$. Values are amounts eaten by six fish per aquarium over 6 days, expressed as percentages of initial wet food weights offered.

\begin{tabular}{|c|c|c|c|c|}
\hline Aquarium & $\begin{array}{c}\text { Fila- } \\
\text { mentous } \\
\text { algae }\end{array}$ & $\begin{array}{l}\text { Najas } \\
\text { guada- } \\
\text { lupensis }\end{array}$ & $\begin{array}{c}\text { Elodea } \\
\text { nuttallii }\end{array}$ & $\begin{array}{l}\text { Cerato- } \\
\text { phyllum } \\
\text { demersum }\end{array}$ \\
\hline \multicolumn{5}{|c|}{ Run 1: $35 \mathrm{~g}$ offered of each food ${ }^{\mathrm{a}}$} \\
\hline 1 & 100 & 71 & 3 & 29 \\
\hline 2 & 100 & 74 & 43 & 11 \\
\hline 3 & 100 & 97 & 51 & 14 \\
\hline Mean & 100 & 81 & 32 & 18 \\
\hline \multicolumn{5}{|c|}{ Run 2: $70 \mathrm{~g}$ offered of each food ${ }^{\mathrm{b}}$} \\
\hline 1 & 100 & 73 & & \\
\hline 2 & 100 & 89 & & \\
\hline 3 & 100 & 100 & & \\
\hline Mean & 100 & 87 & & \\
\hline \multicolumn{5}{|c|}{ Run 3: $70 \mathrm{~g}$ offered of each food } \\
\hline 1 & & & 33 & 17 \\
\hline 2 & & & 71 & 14 \\
\hline 3 & & & 93 & 51 \\
\hline Mean & & & 66 & 27 \\
\hline
\end{tabular}

a Filamentous algae were all consumed by day 6 .

b Filamentous algae were all consumed by day 5 . 